\title{
Características produtivas, morfogênicas e estruturais do capim Piatã submetido à adubação orgânica
}

\author{
Structural, morphogenetic and productive features of Piatã Grass \\ subjected to organic fertilization
}

\author{
Marco Antonio Previdelli Orrico Junior ${ }^{\mathrm{I}}$ Stanley Ribeiro Centurion ${ }^{\mathrm{II}}$ \\ Ana Carolina Amorim Orrico ${ }^{\text {III }}$ Arley Borges de Morais Oliveira ${ }^{\mathrm{II}}$ Natália da Silva Sunada ${ }^{\mathrm{IV}}$
}

RESUMO

A adubação orgânica pode ser uma alternativa viável na produção de gramíneas forrageiras, no entanto poucas são as informações referentes às doses e à composição dos principais adubos orgânicos. O objetivo do trabalho foi verificar a influência das diferentes doses de composto orgânico produzido com dois tipos de cama de frango sobre as características produtivas, morfogênicas e estruturais de Brachiaria brizantha, cv 'Piatã'. O experimento foi conduzido em casa de vegetação em delineamento inteiramente casualizado, em esquema fatorial com parcela subdividida no tempo. As parcelas foram compostas por seis tratamentos: dois tipos compostos (cama de frango a base de cana de açúcar ou napier) em três doses (100, 200 e 300 $\mathrm{kg} \mathrm{ha}^{-1}$ equivalente $N$ ) e as subparcelas pelos quatro períodos de cortes. Os compostos foram aplicados em dose única, após o corte de uniformização, nas quantidades de: 11,36 e 11,83, 22,73 e 23,67,

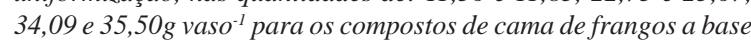
de cana de açúcar e capim napier, respectivamente, que equivalem às doses de 100, 200 e $300 \mathrm{~kg} \mathrm{ha}^{-1}$ de $\mathrm{N}$. As variáveis mensuradas foram: produção de matéria seca (PMS), taxa de aparecimento de folha (TApF), taxa de alongamento de folha (TAlF), filocrono, taxa de alongamento de pseudocolmo (TAlC), comprimento final de folha (CFF) e números de folhas verdes (NFV). Não foi observada diferença significativa entre os tipos de composto e na interação composto x dose. Dessa forma, ambos poderiam ser utilizados sem que ocorresse prejuízo no aproveitamento dos nutrientes pelas plantas avaliadas no experimento. Houve diferença significativa entre a PMS, TApF, filocrono, TAlF e TAIC, NFV e TFF em função das doses crescentes de nitrogênio, segundo um modelo linear de predição. Também foi observado efeito dos períodos de corte, em que os cortes realizados no verão apresentaram melhor desempenho sobre as características morfogênicas e estruturais.

Palavras-chave: Brachiaria brizantha, filocrono, matéria seca, nitrogênio.

\section{ABSTRACT}

The organic fertilizer can be a viable alternative in the production of forage grasses, however there is little information regarding doses and composition of the major organic fertilizers. The aim of this paper was to verify the influence of the different doses of organic compost produced from two types of poultry litter on the structural, morphogenetic and productive characteristics of Brachiaria brizantha $c v$ 'Piatã'. The experiment was conducted in a greenhouse in a completely randomized design in a factorial scheme l with parcel subdivided in time. The parcels were composed by six treatments: two types of compost (poultry litter based in sugar cane and napier grass) in three doses (100, 200 and $300 \mathrm{~kg} \mathrm{ha}^{-1}$ equivalent $\mathrm{N}$.) and the subparcels by the four different periods of cut. The composts were applied in a unique dose, after the uniformization cut, at the quantities: 11,36 and 11,83, 22,73 and 23,67, 34,09 and 35,50 $\mathrm{g} \mathrm{pot}^{-1}$ for the poultry litter based in sugar cane and napier grass, respectively which are equivalent to the rates of 0,100, 200 and $300 \mathrm{~kg} \mathrm{ha}^{-1}$ of $N$. The variables measured were: dry matter production (DMP), leaf appearance rate (LApR), phyllochron, leaf elongation dose (LER) and shoots elongation rate (SER), number of green leaves (NGL), final size of the leaf (FSL). No significant difference between the types of composts and in the interaction compost $x$ doses was observed, thus, both could be used without the risk of loss in the use of the nutrients by the plants evaluated in the experiment. There was a significant difference between the DMP, LApR, phyllochron, LER, SER, NGL and FSL because of the increasing rates of nitrogen, followed by a linear model of prediction. The effect of the periods of slaughter was also observed, where the slaughters carried out in the summer presented a better performance over the morphogenetic and structural features evaluated.

Key words: Brachiaria brizantha, phyllochron, dry matter, nitrogen.

IPrograma de Pós-graduação em Zootecnia, Universidade Federal da Grande Dourados (UFGD), 79804-970, Dourados, MS, Brasil. E-mail: marcoorrico@yahoo.com.br. Autor para correspondência.

IIPrograma de Pós-graduação em Zootecnia, UFGD, Dourados, MS, Brasil.

IIICurso de Zootecnia, Faculdade de Ciências Agrárias, UFGD, Dourados, MS, Brasil.

${ }^{\text {IV }}$ Programa de Pós-graduação em Zootecnia, Universidade Estadual Paulista (UNESP), campus de Jaboticabal, Jaboticabal, SP, Brasil. 


\section{INTRODUÇÃO}

Durante muito tempo, a cama de frangos in natura foi utilizada na alimentação de ruminantes, ou mesmo na adubação de pastagem, sendo inclusive muito difundida e incentivada no país, até a sua proibição em 2001 pela Instrução Normativa nำ15 do Ministério da Agricultura, Pecuária e Abastecimento, como uma das medidas preventivas para se evitar no país os riscos potenciais da encefalopatia espongiforme bovina (DUTRA et al., 2005). Após essa data, a cama só poderia ser utilizada na adubação de áreas agrícolas. Desta forma, os avicultores tiveram que dar destino diferente para a cama de frango produzida. O destino mais apropriado para esse resíduo é a técnica da compostagem, que, além de apresentar como vantagens a redução de massa, volume e microrganismos patogênicos, permite a obtenção de um produto final com excelentes características fertilizantes, as quais devem ser aproveitadas de maneira consciente para a produção vegetal. A maior parte dos solos das regiões tropicais apresenta baixa fertilidade natural, devido principalmente aos baixos teores de matéria orgânica e de P disponível (SOUTO et al., 2005). Assim, os resíduos orgânicos podem ser aplicados ao solo para aumentar o teor de nutrientes disponíveis para as plantas e, inclusive, caso sejam aplicadas doses frequentes ao longo dos anos, podem incrementar o teor de carbono orgânico total no solo, especialmente naqueles com histórico de degradação (SOUTO et al., 2005).

No entanto, para que se possa utilizar o composto na adubação, é necessário o conhecimento da resposta da planta às diferentes doses, pois assim será possível estabelecer quantidades que promovam o maior desenvolvimento da planta, sem ocasionar o excesso de nutrientes no solo (SOUTO et al., 2005). Além das doses de composto, é necessário saber qual a disponibilidade dos nutrientes presentes neste, visto que isso depende do processo de mineralização do material. Esse processo de mineralização é influenciado por características do material orgânico e pelas condições ambientais de temperatura, umidade, aeração e acidez (CORREIA \& ANDRADE, 1999). O objetivo do trabalho foi definir o melhor tipo e a melhor dose de composto orgânico para proporcionar melhorias nas características produtivas, morfogênicas e estruturais de Brachiaria brizantha, cv 'Piatã'.

\section{MATERIAL E MÉTODOS}

O experimento foi instalado na casa de vegetação pertencente à Faculdade de Ciências Agrárias da Universidade Federal da Grande Dourados (UFGD), localizada no município de Dourados (MS). Os dados meteorológicos referentes à temperatura, umidade e radiação observados dentro da estufa durante o experimento estão apresentados na tabela 1.

O solo utilizado foi um Latossolo Vermelho Distroférrico (Embrapa, 2006), coletado em uma área da UFGD sem histórico de cultivo. O solo coletado foi disposto em um pátio para secagem e posteriormente foi passado em peneira com malha de $5 \mathrm{~mm}$. Após esse processo, uma amostra representativa do solo foi encaminhada ao laboratório de solos da instituição para a realização das análises químicas e físicas do solo (EMBRAPA, 1997). Os resultados foram os seguintes: $\mathrm{pHCaCl}_{2}=4,3 ; \quad \mathrm{P}($ resina $)=0 \mathrm{mg} \quad \mathrm{dm}^{-3} ; \quad \mathrm{K}=0,3 \mathrm{mmol}$ $\mathrm{dm}^{-3} ; \quad \mathrm{Ca}=4,0 \mathrm{mmol} \quad \mathrm{dm}^{-3} ; \quad \mathrm{Mg}=3,0 \mathrm{mmol} \quad \mathrm{dm}^{-3}$; $\mathrm{Al}+\mathrm{H}=94,0 \mathrm{mmol} \mathrm{dm}^{-3}$; soma de bases $=7,3 \mathrm{mmol} \mathrm{dm}^{-3}$ e CTC $101,3 \mathrm{mmol} \mathrm{dm}^{-3}$; saturação por bases $=7,3 \%$; matéria orgânica $=47,1 \mathrm{~g} \quad \mathrm{dm}^{-3}$; areia $=120 \mathrm{~g} \mathrm{~kg}^{-1}$; silte $=728 \mathrm{~g} \mathrm{~kg}^{-1}$; argila $=152 \mathrm{~g} \mathrm{~kg}^{-1}$. Considerando os resultados da análise química do solo, foi realizada

Tabela 1 - Dados meteorológicos coletados durante todo o período experimental.

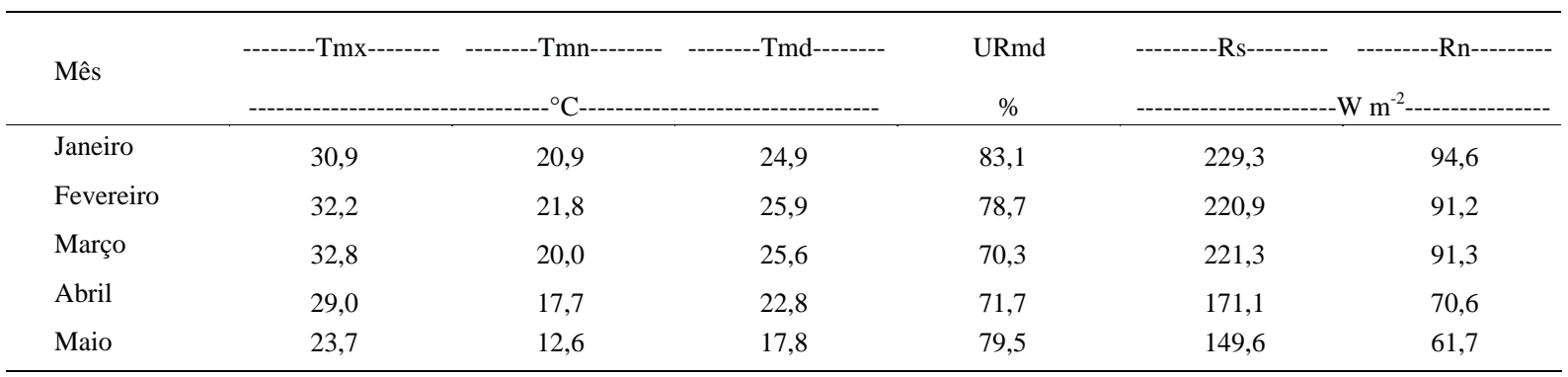

Fonte: Estação meteorológica UFGD. Tmx: Temperatura máxima; Tmn: Temperatura mínima; Tmd: Temperatura média; URmd: Umidade relativa média; Rs: Radiação solar; Rn: Radiação líquida. 
a calagem 60 dias antes do plantio com o intuito de elevar a saturação de bases para 50\%. Para isso, foram utilizados 1,96g dm ${ }^{-3}$ de calcário filer (95\% de PRNT). Devido à baixa fertilidade do solo utilizado no experimento, foi realizada uma adubação de formação para garantir o estabelecimento da forrageira. Foram aplicados (misturado ao solo) $204 \mathrm{mg} \mathrm{dm}^{-3}$ de $\mathrm{N}$, $818 \mathrm{mg} \mathrm{dm}^{-3}$ de $\mathrm{P}_{2} \mathrm{O}_{5}$ e $187 \mathrm{mg} \mathrm{dm}^{-3}$ de $\mathrm{K}_{2} \mathrm{O}$, na forma de uréia, superfosfato simples e cloreto de potássio, respectivamente. A umidade dos vasos foi controlada a cada três dias, através da pesagem destes, sempre visando a manter o solo com $70 \%$ da capacidade de campo. A irrigação foi feita com água destilada, no intuito de evitar a interferência dos nutrientes presentes na água comum.

O experimento foi conduzido em delineamento inteiramente casualizado em esquema fatorial com parcela subdividida no tempo. As parcelas foram compostas por seis tratamentos: dois tipos compostos (composto a base de cama de cana de açúcar e napier) em três doses (100, 200 e 300kg ha $^{-1}$ equivalente $\mathrm{N}$, com base na análise de $\mathrm{N}$ total dos compostos) e as subparcelas pelos quatro diferentes períodos de cortes. O critério usado para definir as doses de $\mathrm{N}$ foram resultados de outros estudos, que, apesar de divergirem quanto às recomendações, possuíram em comum a dose mínima de $100 \mathrm{~kg}$ de $\mathrm{N}$ $\mathrm{ha}^{-1}$. Cada tratamento continha seis repetições (vaso), totalizando 36 vasos plásticos (vedados para evitar lixiviação dos nutrientes do solo) com capacidade para $9 \mathrm{dm}^{3}$ de solo.

A semeadura foi realizada no dia 02 de janeiro de 2010, sendo semeadas dez sementes de Brachiaria brizantha cv 'Piatã' por vaso e, sete dias após a emergência, fez-se o desbaste, deixando-se três plantas por vaso. $\mathrm{O}$ corte de uniformização foi realizado 45 dias após o plantio (17 de fevereiro de 2010) a $15 \mathrm{~cm}$ da superfície do solo. A partir dessa data (17 de fevereiro de 2010), iniciou-se o período experimental com a aplicação em dose única de 11,36 e 11,83, 22,73 e 23,67, 34,09 e 35,50 para os compostos de cama de frangos a base de cana de açúcar e capim napier, respectivamente, que equivalem às doses de 100,200 e $300 \mathrm{~kg} \mathrm{ha}^{-1}$ de $\mathrm{N}$, equivalente a 50, 100 e $150 \mathrm{mg} \mathrm{dm}^{-3}$ de $\mathrm{N}$. Os compostos utilizados no experimento passaram pelo processo de compostagem durante um período de 70 dias e possuíam teores na matéria seca de 3,78 e $3,63 \%$ de $\mathrm{N} ; 2,23$ e $2,27 \%$ de $\mathrm{P}$ e 0,94 e $0,96 \%$ de $\mathrm{K}$, nos compostos de cama de frangos a base de cana de açúcar e capim napier, respectivamente. Para determinar os teores de nitrogênio, fósforo e potássio dos compostos, foi realizada uma digestão em digestor
Digesdahl Hach a base de ácido sulfúrico $\left(\mathrm{H}_{2} \mathrm{SO}_{4}\right)$ e peróxido de hidrogênio $\left(\mathrm{H}_{2} \mathrm{O}_{2}\right)$ a 50\% APHA (2005). Com esse extrato, foi possível a determinação dos teores de N, P e K, segundo metodologia descrita pela APHA (2005).

A massa de forragem produzida foi medida como sendo o peso total da forragem verde retirada dos vasos após o corte a $15 \mathrm{~cm}$ do solo. O material ceifado foi levado ao laboratório para realizar a secagem em estufa de circulação forçada a uma temperatura de $65^{\circ} \mathrm{C}$ por 48 horas, no intuito de obter o teor de matéria seca (MS) para o cálculo da produção de MS por vaso. O estudo das características morfogênicas e estruturais foi realizado utilizandose dois perfilhos por vaso, identificados com fios coloridos. Este estudo iniciou-se no terceiro dia após o corte de uniformização, com medições a cada três dias, até que as plantas atingissem a altura de corte de $30 \mathrm{~cm}$, deixando um resíduo de $15 \mathrm{~cm}$ (PEDREIRA et al., 2007). Após o corte, outros perfilhos foram escolhidos e iniciava-se a avaliação do próximo corte. Para determinação das características morfogênicas e estruturais, foram registrados dados referentes ao aparecimento do ápice foliar, ao dia da exposição da lígula, comprimento do pseudocolmo, comprimento da lâmina foliar expandida e em expansão, número de folhas por perfilho, número de perfilhos por vaso e número de folhas verdes, mortas e em senescência. Com esses dados, foi possível calcular as seguintes variáveis: a taxa de alongamento foliar (TAlF) foi calculada com base no comprimento total de folhas produzidas pelo número de dias envolvidos; a taxa de aparecimento foliar (TApF) foi obtida pela divisão entre o número de folhas surgidas nos perfilhos marcados e o número de dias envolvidos, enquanto o filocrono correspondeu à forma inversa de cálculo da TApF; a taxa de alongamento do pseudocolmo (TAlC) foi calculada com sendo a diferença entre altura inicial e final (calculado com base no nível do solo até a lígula da última folha expandida de cada perfilho) pelo número de dias envolvidos; o comprimento final de folha (CFF) foi calculado como sendo a média dos comprimentos das lâminas foliares completamente expandidas, desde sua inserção na lígula até o ápice foliar; o número de folhas verdes (NFV) foi obtido por meio da contagem do número de folhas em expansão e expandidas verdes nos perfilhos marcados; a duração de vida da folha (DVF): estimada considerando o tempo entre o aparecimento do ápice foliar e o primeiro sinal de senescência da lâmina, portanto, o tempo que a folha permaneceu verde.

O efeito dose equivalente de nitrogênio foi avaliado por análise de regressão, o efeito do tipo 
de composto foi comparado pelo teste $\mathrm{F}$ e os efeitos dos diferentes períodos de cortes foram avaliados por meio do teste de Scott-Knott, a 1\% de probabilidade.

\section{RESULTADOS E DISCUSSÃO}

Por ter sido utilizado como critério para o corte da forrageira a altura de $30 \mathrm{~cm}$ e não um intervalo de tempo pré-definido, houve diferenças nos tempos em que os tratamentos foram ceifados durante todo experimento (Tabela 2). Mesmo com a variação entre intervalos de corte, não foi observado em nenhum tratamento a senescência de folhas, o que acabou impedindo de calcular a duração média de vida das folhas. SILVEIRA et al. (2010), ao comparar oito cultivares de Brachiaria brizanta em crescimento livre, descobriu que a Brachiaria brizantha cv 'Piatã' é a que apresenta maior longevidade de folha (78 dias), o que explica o fato de não ter sido observada a senescência de folha durante o experimento.

Não foi observada diferença significativa $(P>0,01)$ entre os tipos de compostos e nas interações composto $\mathrm{x}$ dose e composto $\mathrm{x}$ período de corte sobre os parâmetros avaliados em Brachiaria brizantha cv 'Piatã'. Dessa forma, pode-se afirmar que os compostos oriundos de camas de frango a base de cana de açúcar e napier, desde que utilizados de maneira padronizada (corrigindo a dose de acordo com o teor de $\mathrm{N}$ de cada composto), não apresentam diferenças no que diz respeito ao aproveitamento dos nutrientes, proporcionando assim um crescimento similar entre as plantas avaliadas.

Com relação às diferentes doses de composto foram observadas diferenças significativas $(\mathrm{P}<0,01)$ na produção de matéria seca à medida que se aumentou a dose de nitrogênio nos vasos, seguindo um modelo linear de predição, segundo a equação $y=7,6261+0,2301 x$ (r2=0,85). A produção de matéria seca foi $140 \%$ maior no tratamento com $300 \mathrm{~kg} \mathrm{ha}^{-1}$ de $\mathrm{N}$, quando comparado com $100 \mathrm{~kg} \mathrm{ha}^{-1}$ de N. BARNABÉ (2001) observou um aumento de $156 \%$ na produção de matéria seca, no entanto, o autor comparou a dose máxima utilizada de efluente de lagoa de estabilização de suinocultura com a testemunha (sem adubação), em pastagem de Brachiaria brizantha cv 'Marandu'. Os autores também encontraram um comportamento linear entre a produção de matéria seca e as doses de efluente de lagoa de estabilização de suinocultura.

As variáveis morfogênicas e estruturais também foram afetadas $(\mathrm{P}<0,01)$ pelas doses de compostos, seguindo também um comportamento linear, conforme os dados da tabela 3. Existem na literatura dados muito variados no que se refere ao comportamento das variáveis morfogênicas e estruturais, frente a diferentes doses de nitrogênio. ALEXANDRINO et al. (2004) encontrou comportamento linear entre as características morfogênicas e estruturais de Brachiaria brizantha cv 'Marandu' com as doses de 0, 20 e 40mg dm ${ }^{3}$ semana $^{-1}$ de N. Já SILVA et al. (2009) encontraram, para mesma espécie e mesmas variáveis analisadas, um modelo quadrático de predição. Os motivos de tanta variação podem estar relacionados à época do ano em que o experimento foi realizado, à fertilidade do solo (quantidade residual de nutrientes) e ao tipo de vaso utilizado (perfurado não impede a lixiviação dos nutrientes). Outro ponto que deve ser levado em consideração é a faixa em que os dados são testados, dessa forma, quanto maior for a dose de $\mathrm{N}$ aplicada nos vasos, maior será a chance de haver um comportamento quadrático. Foi o que aconteceu com SILVA et al. (2009), citados anteriormente, quando os autores utilizaram uma faixa de avaliação que foi até $380 \mathrm{~kg} \mathrm{ha}^{-1}$ de $\mathrm{N}$, ou seja, $80 \mathrm{~kg} \mathrm{ha}^{-1}$ de $\mathrm{N}$ superior à utilizada neste trabalho. Dessa forma, foi possível encontrar o ponto máximo de crescimento da forragem.

Foi observado incremento de 54\% na TAlF para as plantas que receberam a maior dose de $\mathrm{N}$, em relação à menor dose de $\mathrm{N}$. Esse incremento é responsável, em grande parte, pelo aumento da

Tabela 2 - Intervalo entre cortes (dias) em função da dose de nitrogênio e dos diferentes períodos de corte de Brachiaria brizantha cv 'Piatã'.

\begin{tabular}{|c|c|c|c|c|}
\hline Dose $\mathrm{kg} \mathrm{ha}^{-1}$ de $\mathrm{N}$ & $1^{\circ}$ corte & $2^{\circ}$ corte & $3^{\circ}$ corte & $4^{\circ}$ corte \\
\hline 0 & 20 & 24 & 28 & 35 \\
\hline 100 & 18 & 21 & 22 & 31 \\
\hline 200 & 14 & 18 & 21 & 30 \\
\hline 300 & 13 & 15 & 16 & 26 \\
\hline
\end{tabular}


produção de massa seca (Tabela 3), que está em função do aumento da área foliar, e, provavelmente, pela melhor relação entre carbono e nitrogênio para a rebrotação (ALEXANDRINO et al, 2004). A TAlF está diretamente relacionada à produção de massa seca, como descrita por GOMIDE (1997), e, por sua vez, explica grande parte do maior volume de forragem produzido.

A TApF aumentou de 0,13 folhas perfilho-1 dia $^{-1}$ para 0,17 folhas perfilho ${ }^{-1}$ dia $^{-1}$ para as plantas que receberam a maior dose de $\mathrm{N}$, em relação às que receberam a menor dose. LEMAIRE \& CHAPMAN (1996) afirmaram que há uma relação direta da TApF com a densidade populacional de perfilhos, o que determina o potencial de perfilhamento de dado genótipo, pois cada folha formada representa potencialmente o surgimento de um novo perfilho, ou seja, a geração de novas gemas axilares. Consequentemente, se novos perfilhos são gerados, espera-se que altas doses de $\mathrm{N}$ promovam maior acúmulo de MS, pois há aumento no índice de área foliar do pasto, ou seja, biomassa aérea. O filocrono é definido como o tempo gasto para a formação de uma nova folha, ou seja o inverso da TApF. Dessa forma, foi observada redução no valor do filocrono de 8,51 para 6,81 dias nas doses de 100 e $300 \mathrm{~kg} \mathrm{ha}^{-1}$ de $\mathrm{N}$, respectivamente. ALEXANDRINO et al. (2004), avaliando o filocrono em Brachiaria. brizantha cV 'Marandu', verificaram que, com o aumento das doses de nitrogênio, o filocrono reduziu de 12,20 para 6,99 dias, respectivamente, nas plantas adubadas com 0 a $40 \mathrm{mg} \mathrm{dm}^{-3}$ semana $^{-1}$ de $\mathrm{N}$.
Os resultados obtidos neste trabalho devem ser avaliados com cautela, pois o aumento constante da dose de composto orgânico (equivalente $\mathrm{N}$ ) pode levar ao excesso de nutrientes (oferta maior que a demanda pelas plantas) no solo e consequente contaminação do lençol freático pela lixiviação (ANDRADE et al., 2005).

Foi observado o efeito $(\mathrm{P}<0,01)$ dos períodos de corte sobre as características produtivas, morfogênicas e estruturais do capim Piatã (Tabela 3). O primeiro corte foi o que apresentou os maiores valores de TAlF, TApF, TAlC, CFF, NFV e menores filocrono, sendo que esses valores foram se alterando à medida que se realizavam os cortes, ou seja, sofriam redução à medida que terminava o verão e iniciava o outono. Segundo EUCLIDES et al. (2008), esse padrão de variação é típico das regiões tropicais, em consequência da estacionalidade das chuvas, variações de temperatura e fotoperíodo, visto que, no caso específico do experimento em questão, houve apenas a influência da temperatura (Tabela 1) e fotoperíodo, pois a umidade do solo foi controlada durante todo período experimental.

Houve uma redução de 35,91 e 33,33\% na TAlF e TApF, respectivamente, na comparação do primeiro com o ultimo corte. BARBOSA (2004) observou maiores valores de TAlF e TApF durante o verão e consequentemente maiores valores de filocrono durante inverno. Segundo GASTAL et al. (1992), as taxas de aparecimento e alongamento de folhas aumentam

Tabela 3 - Efeito das diferentes doses de nitrogênio e dos diferentes períodos de corte sobre as características produtivas, morfogênicas e estruturais de Brachiaria brizantha cV 'Piatã'.

\begin{tabular}{|c|c|c|c|c|c|}
\hline Características & \multicolumn{2}{|c|}{ Equações de predição } & \multicolumn{2}{|c|}{$r^{2}$} & $\mathrm{p}$ \\
\hline Matéria Seca $\left(\right.$ g vaso $^{-1}$ ) & \multicolumn{2}{|c|}{$Y=0,2301 N+7,6261$} & \multicolumn{2}{|c|}{0,85} & $* *$ \\
\hline TAlF (cm perfilho ${ }^{-1}$ dia $^{-1}$ ) & \multicolumn{2}{|c|}{$Y=0,0138 N+3,8715$} & \multicolumn{2}{|c|}{0,74} & $* *$ \\
\hline TAlC (cm perfilho ${ }^{-1}$ dia $^{-1}$ ) & \multicolumn{2}{|c|}{$\mathrm{Y}=0,002 \mathrm{~N}+0,3074$} & \multicolumn{2}{|c|}{0,78} & $* *$ \\
\hline TApF (folhas perfilho-1 dia $^{-1}$ ) & \multicolumn{2}{|c|}{$Y=0,0002 N+0,1142$} & \multicolumn{2}{|c|}{0,76} & $* *$ \\
\hline Filocrono (dias) & \multicolumn{2}{|c|}{$Y=-0,0117 N+10,325$} & \multicolumn{2}{|c|}{0,87} & $* *$ \\
\hline CFF (cm perfilho ${ }^{-1}$ ) & \multicolumn{2}{|c|}{$Y=0,0573 N+16,269$} & \multicolumn{2}{|c|}{0,88} & $* *$ \\
\hline NFV (folhas ${ }^{-1}$ perfilho $^{-1}$ ) & \multicolumn{2}{|c|}{$Y=0,0055 N+3,9611$} & \multicolumn{2}{|c|}{0,75} & $* *$ \\
\hline Características & $1^{\circ}$ corte & $2^{\circ}$ corte & $3^{\circ}$ corte & $4^{\circ}$ corte & $\mathrm{CV} \%$ \\
\hline Matéria Seca (g vaso ${ }^{-1}$ ) & 43,67B & $39,10 \mathrm{~B}$ & $65,23 \mathrm{~A}$ & $50,99 B$ & 18,38 \\
\hline TAlF (cm perfilho ${ }^{-1}$ dia $^{-1}$ ) & $9,41 \mathrm{~A}$ & $8,46 \mathrm{~A}$ & $7,01 \mathrm{~B}$ & $6,03 \mathrm{C}$ & 11,85 \\
\hline TAlC (cm perfilho ${ }^{-1}$ dia $^{-1}$ ) & $1,01 \mathrm{~A}$ & $0,90 \mathrm{~A}$ & $0,82 \mathrm{~B}$ & $0,67 \mathrm{C}$ & 12,23 \\
\hline TApF (folhas perfilho ${ }^{-1} \mathrm{dia}^{-1}$ ) & $0,21 \mathrm{~A}$ & $0,20 \mathrm{~A}$ & $0,16 \mathrm{~B}$ & $0,14 \mathrm{C}$ & 8,27 \\
\hline Filocrono (dias) & $5,14 \mathrm{C}$ & $5,44 \mathrm{C}$ & $6,57 \mathrm{~B}$ & 7,84 A & 13,45 \\
\hline CFF (cm perfilho ${ }^{-1}$ ) & $30,33 \mathrm{~A}$ & $29,03 \mathrm{~A}$ & 26,94B & $26,81 B$ & 8,90 \\
\hline NFV (folhas ${ }^{-1}$ perfilho $^{-1}$ ) & $5,70 \mathrm{~A}$ & $4,89 \mathrm{~B}$ & 4,83 B & $4,28 \mathrm{C}$ & 7,80 \\
\hline
\end{tabular}

$\mathrm{P}=$ significância ; **= 1\%de probabilidade; $\mathrm{r}^{2}=$ coeficiente de determinação do modelo; CV\%= coeficiente de variação. Na linha, letras distintas diferem entre si pelo teste de Scott-Knott a $1 \%$ de probabilidade. 
conforme aumenta a temperatura do meio. Dessa forma, o tamanho final da folha, que é determinado pela relação taxa de alongamento/taxa de aparecimento, eleva-se com o aumento da temperatura, fazendo com que as folhas crescidas no verão apresentem maior tamanho em comparação com as outras estações do ano. Esse padrão também foi observado neste experimento, já que as folhas apresentavam em média $30,33 \mathrm{~cm}$ de comprimento no primeiro corte e $26,81 \mathrm{~cm}$ no último corte.

Foram observadas diferenças significativas $(\mathrm{P}<0,01)$ no NFV durante os diferentes períodos de corte, sendo constatada uma redução no NFV, quando se compara os cortes feitos durante o verão e os feitos durante o outono (Tabela 3). O NFV é uma variável determinada geneticamente, e cada espécie ou cultivar mantém seu NFV independente do manejo imposto. No entanto, limitações de temperatura e fotoperíodo promovem reduções nesses valores, pois a TApF, que também determina o NFV, é reduzida (HODGSON, 1990).

Assim como as demais características avaliadas, a TAlC também sofreu influência ao longo dos cortes. A TAlC é uma importante característica observada nas gramíneas tropicais de hábito ereto, a qual interfere significativamente na estrutura do dossel forrageiro e no processo de competição por luz (SBRISSIA \& SILVA, 2001). Essa característica é influenciada enormemente pelo alongamento ou pela duração do alongamento de cada folha, ou seja, quanto maior for a duração do filocrono menor será a TAlC (Tabela 3). Esse comportamento foi observado no experimento em que foram encontrados valores de TAlC de 1,01 e $0,67 \mathrm{~cm}_{\text {perfilho }}{ }^{-1} \mathrm{dia}^{-1}$ para o primeiro e quarto cortes, que foram os que obtiveram o menor e maior filocrono, respectivamente.

\section{CONCLUSÃO}

As características produtivas, morfogênicas e estruturais da Brachiaria brizantha cv 'Piatã' responde de forma crescente até a dose de $300 \mathrm{~kg}$ $\mathrm{ha}^{-1}$ de nitrogênio, independente da fonte utilizada, na forma de compostos oriundos de camas de frango a base de cana de açúcar e napier. A queda na temperatura e no fotoperíodo, observada durante o experimento, influenciou nas características morfogênicas e estruturais da Brachiaria brizantha cV 'Piatã'.

\section{REFERÊNCIAS}

ALEXANDRINO, E. et al. Características morfogênicas e estruturais na rebrotação da Brachiaria brizantha cv. 'Marandu' submetida a três doses de nitrogênio. Revista Brasileira de
Zootecnia, v.33, n.6, p.1372-1379, 2004. Disponível em: $<$ http://www.scielo.br/scielo.php?script=sci_arttext\&pid=S151635982004000600003\&lng=en\&nrm=iso>. Acesso em: 30 set. 2010. doi: 10.1590/S1516-35982004000600003.

AMERICAN PUBLIC HEALTH ASSOCIATION (APHA). Standard methods for examination of water and wastewater. Washington: American Water Works Association, 2005. 1368p.

ANDRADE, I.P. et al. Impacto do reúso de efluentes de esgoto no lixiviado de solos cultivados com milho. Revista Brasileira de Engenharia Agrícola e Ambiental, v.9, p.212-216, 2005.

BARBOSA, R.A. Características morfofisiológicas e acúmulo de forragem em capim-Tanzânia (Panicum maximum Jacq. cv. 'Tanzânia') submetido a freqüências e intensidades de pastejo. 2004. 122f. Tese (Doutorado em Zootecnia) - Curso de Pósgraduação em Zootecnia, Universidade Federal de Viçosa, MG.

BARNABÉ, M.C. Produção e composição bromatológica da Brachiaria brizantha cv. 'Marandu' adubada com dejetos líquidos de suínos. 2001. 67f. Dissertação (Mestrado em Ciência Animal) - Curso de Pós-graduação em Ciência Animal, Universidade Federal de Goiás, GO.

CORREIA, M.E.F.; ANDRADE, A.G. Formação de serapilheira e ciclagem de nutrientes. In: SANTOS, G. de A.; CAMARGO, F.A. de O. (Ed.). Fundamentos da matéria orgânica do solo: ecossistemas tropicais e subtropicais. Porto Alegre: Gênesis, 1999. p.197-225.

DUTRA, I.S. et al. Botulismo em bovinos de corte e leite alimentados com cama de frango. Pesquisa Veterinária Brasileira, v.25, n.2, p.115-119, 2005. Disponível em: <http:// www.scielo.br/scielo.php?script=sci_arttext\&pid=S0100-736X20 07000400005\&lng=pt\&nrm=iso $>$. Acesso em: 30 set. 2010. doi: 10.1590/S0100-736X2007000400005.

EMPRESA BRASILEIRA DE PESQUISA AGROPECUÁRIA (EMBRAPA). Sistema brasileiro de classificação de solos. 2.ed. Rio de Janeiro: Embrapa Solos, 2006. 306p.

EMPRESA BRASILEIRA DE PESQUISA AGROPECUÁRIA (EMBRAPA). Manual de métodos de análise de solo. 2.ed. Rio de Janeiro, 1997. 212p.

EUCLIDES, V.P.B. et al. Produção de forragem e características da estrutura do dossel de cultivares de Brachiaria brizantha sob pastejo. Pesquisa. Agropecuária Brasileira, v.43, n.12, p.1805-1812 2008. Disponível em: <http://www.scielo.br/scielo. php?script=sci_arttext\&pid=S0100-204X2008001200023\&lng =pt\&nrm=iso $>$. Acesso em: 30 set. 2010. doi: 10.1590/S0100204X2008001200023.

GASTAL, F. et al. A model of the leaf extension rate of tall fescue in response to nitrogen and temperature. Annals of Botany, v.70, p.437-442, 1992.

GOMIDE, J.A. Morfogênese e análise de crescimento de gramíneas tropicais. In: SIMPÓSIO INTERNACIONAL SOBRE PRODUÇÃO ANIMAL EM PASTEJO, 1997, Viçosa, MG. Anais... Viçosa: Universidade Federal de Viçosa, 1997. CDROM.

HODGSON, J. Grazing management: science into practice. New York: John Wiley \& Sons, 1990. 203p. 
LEMAIRE, G. et al. Tissue flows in grazed plant communities. In: HODGSON, J.; ILLIUS, A.W. The ecology and management of grazing systems. New York: Cab International, 1996. Cap 1, p.03-36.

PEDREIRA, B.C. et al. Estrutura do dossel e acúmulo de forragem de Brachiaria brizantha cultivar 'Xaraés' em resposta a estratégias de pastejo. Pesquisa Agropecuária Brasileira, v.42, n.2, p.281-287, 2007. Disponível em: <http://www.scielo.br/ scielo.php?script=sci_arttext\&pid=S0100204X2008001200023\&l ng=en\&nrm=iso>. Acesso em: 30 set. 2010. doi: 10.1590/S0100204X2008001200023.

SILVA, C.C.F. et al. Características morfogênicas e estruturais de duas espécies de Braquiária adubadas com diferentes doses de nitrogênio. Revista Brasileira de Zootecnia, v.38, n.4, p.657-661, 2009. Disponível em: <http://www.scielo.br/scielo.php?script=sci arttext\&pid=S151635982009000400010\&lng $=$ pt\&nrm=iso $>$. Acesso em: 30 set. 2010. doi: 10.1590/S1516-35982009000400010.
SILVEIRA, M.C.T. et al. Morphogenetic and structural comparative characterization of tropical forage grass cultivars under free growth. Scientia Agrícola, v.67, n.2, p.136-142, 2010. Disponível em: <http://www.scielo.br/scielo.php?script=sci_arttex t\&pid=S0103-90162010000200002 \&lng=en\&nrm=iso>. Acesso em: 30 set. 2010. doi: 10.1590/S0103-90162010000200002.

SOUTO, P.C. et al. Decomposição de estercos dispostos em diferentes profundidades em área degradada no semi-árido da Paraíba. Revista Brasileira de Ciência do Solo, v.29, n.1, p.125-130, 2005. Disponível em: <http://www.scielo.br/scielo. php?script=sci_arttext\&pid=S0100-06832005000100014\&lng =en\&nrm=iso>. Acesso em: 06 ago. 2012. doi:10.1590/S010006832005000100014.

UFV (UNIVERSIDADE Federal de viçosa). Sistema de análises estatísticas e genéticas - SAEG. Versão 8.0. Viçosa, MG, 2000. CD. 